\title{
Twiddler's Syndrome with 180 Degree Extreme Rotation of a Permanent Pacemaker Generator
}

\section{Kalıcı Kalp Pili Jeneratörünün 180 Derece Rotasyonu Şeklindeki Twiddler Sendromu}

Mustafa Yıldız ${ }^{1}$, Mehmet Ali Astarcıoğlu ${ }^{1}$, Mehmet Özkan ${ }^{1}$

${ }_{1}^{1}$ Department of Cardiology, Kosuyolu Heart Center, Kartal, Istanbul, Turkey

${ }^{1}$ Kartal Koşuyolu Yüksek Ihtisas Eğitim ve Araştırma Hastanesi, Kardiyoloji Kliniği, İstanbul, Türkiye

Twiddler's syndrome refers to permanent malfunction of a pacemaker due to the patient's manipulation of the pulse generator ${ }^{(1)}$. Obese and elderly patients appear to be at increased risk because the presence of loose subcutaneous tissue allows for rotation of the pulse generator in its pace pocket ${ }^{(2)}$. A 57 year-old obese woman received a single chamber pacemaker (VVIR) following a diagnosis of high grade atrioventricular block after mitral valve replacement. A pre-discharge chest $\mathrm{X}$-ray revealed the pacemaker generator well positioned in the right infraclavicular area of the chest wall (Figure 1). During follow-up, an electrocardiography revealed loss of capture. The device was mobile in the pocket and there was evidence of traction of the lead (Figure 2). There was an extreme rotation of the pulse generator along the sagittal axis (180 degree). She underwent pocket revision and new lead implantation.

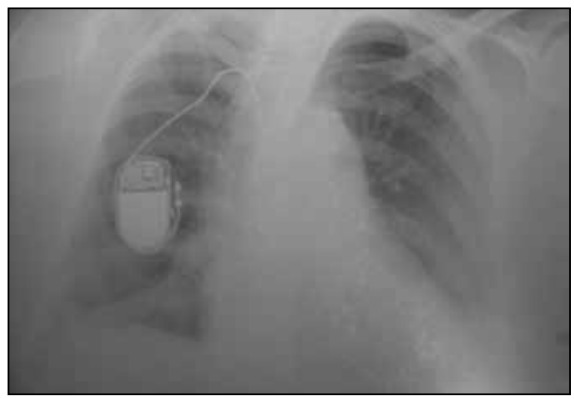

Figure 1. A pre-discharge chest X-ray revealed the pacemaker generator well positioned in the right infraclavicular area of the chest wall.

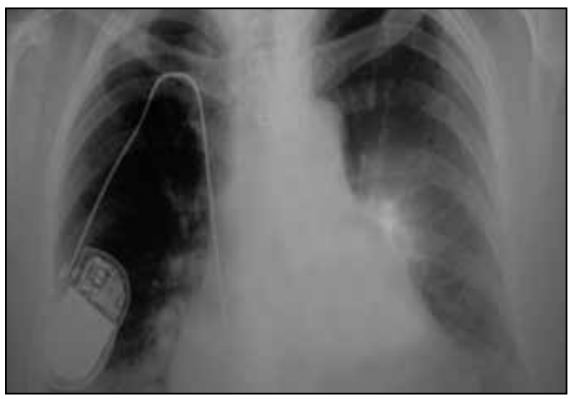

Figure 2. The device was mobile in the pocket and there was evidence of traction of the lead.
Kartal Koşuyolu Yüksek îhtisas Eğitim ve Araştırma Hastanesi,

Kardiyoloji Kliniği,

Denizer Caddesi, Cevizli Kavşağı No: 234846 Cevizli, Kartal, İstanbul-Türkiye

\section{REFERENCES}

1. Bayliss CE, Beanlands DS, Baird RJ. The pacemaker-twiddler's syndrome: a new complication of implantable transvenous pacemakers. Can Med Assoc J 1968;99:371-3.

2. Khalilullah M, Khanna SK, Gupta U, Padmavati S. Pacemaker twiddler's syndrome: a note on its mechanism. J Cardiovasc Surg (Torino) 1979;20:95-100. 